\title{
MÉTODOS EMERGENTES PARA AUMENTAR A EFICIÊNCIA DO OZÔNIO NO TRATAMENTO DE ÁGUAS CONTAMINADAS
}

\author{
Amira Mahmoud e Renato S. Freire* \\ Departamento de Química Fundamental, Instituto de Química, Universidade de São Paulo CP 26077, 05513-970 São Paulo - \\ SP, Brasil. Centro de Capacitação e Pesquisa em Meio Ambiente, Cubatão - SP, Brasil \\ Recebido em 30/9/05; aceito em 6/2/06; publicado na web em 30/8/06
}

\begin{abstract}
NEW METHODS FOR ENHANCING OZONE EFFICIENCY ON CONTAMINATED WATER TREATMENT. Many industrial processes produce effluents with a wide variety of xenobiotic organic pollutants, which cannot be efficiently degraded by conventional biological treatments. Thus, the development of new technologies to eliminate these refractory compounds in water has become very imperative in order to assure the quality of this important resource. Ozonation is a very promising process for the treatment of wastewaters containing non-easily removable organic compounds. The present work aims at highlighting new methods of enhancing the efficiency of ozone towards the removal organic pollutants in aqueous solution. Special attention is given to catalytic ozonation processes contemplating homo- and heterogeneous catalysis, their activity and mechanisms. Recent results and future prospects about the application of these processes to real effluents are also evaluated.
\end{abstract}

Keywords: catalytic ozonation; environmental chemistry; advanced oxidation processes.

\section{INTRODUÇÃO}

Desde as últimas décadas do século passado, a sociedade tem adquirido uma conscientização crescente a respeito dos problemas ambientais e seus efeitos para a qualidade de vida desta e das futuras gerações. Apesar disso, a integridade de vários ecossistemas vem sendo afetada, de maneira preocupante, por uma série de atividades antropogênicas, levando a um risco de degradação irreversível do meio ambiente.

Neste panorama, as preocupações com o uso e a qualidade da água adquirem especial importância devido à relevância deste recurso e ao aumento desenfreado de sua demanda, resultante principalmente do crescimento acelerado da população e estilo de vida da sociedade contemporânea (que dentre outras coisas, prima por padrões de conforto e bem-estar em detrimento do equilíbrio dos recursos naturais). De fato, é difícil imaginar qualquer tipo de organização dos seres humanos em sociedade que dispense o uso da água, uma vez que esta substância é essencial não somente para a manutenção das atividades biológicas básicas (a água compõe parte significativa das células de todos os seres vivos, estando envolvida em processos de transporte de nutrientes e dejetos; manutenção de temperatura; produção e armazenamento de energia, etc.), mas também para o desenvolvimento das atividades produtivas (agrícolas ou industriais).

Talvez por ser relativamente abundante, a água tornou-se tão banal que sua presença, embora indispensável, não desperta a merecida atenção e valorização. Apesar da água ser um recurso natural renovável (qualquer que seja seu uso, no final ela é restituída ao ambiente/origem), durante muito tempo teve-se uma concepção errônea de inesgotabilidade desta substância. Embora seja verdade que o homem não faça a água simplesmente desaparecer da natureza (como tem feito com florestas e algumas reservas minerais), a qualidade de uma infinidade de recursos hídricos tem sido seriamente comprometida ${ }^{1,2}$.

Dentre as várias atividades antrópicas que têm contribuído para a degradação da qualidade das águas, a atividade industrial é, sem

*e-mail: rsfreire@iq.usp.br dúvida alguma, uma das principais fontes de poluição. Isto se deve, dentre vários fatores, à ineficiência dos processos produtivos (a produção/transformação de materiais não é $100 \%$ eficaz, levando à presença inerente de sub-produtos e/ou matéria-prima). Além disso, os processos industriais geralmente utilizam grandes volumes de água, que podem levar à contaminação de corpos d'água, sobretudo pela dificuldade para se tratar grandes quantidades de efluentes. Finalmente, a variedade de compostos oriundos dos processos industriais, que podem comprometer a qualidade de nossas águas, é enorme, indo desde compostos inorgânicos (como os metais pesados) até várias classes de compostos orgânicos (compostos aromáticos, nitrogenados, halogenados, alifáticos, etc), o que praticamente inviabiliza o desenvolvimento de sistemas de tratamento de efluentes que sejam universais (capazes de serem empregados na degradação de qualquer tipo de resíduo) $)^{3,4}$.

Atualmente, as indústrias têm empregado tratamentos baseados em processos físicos e biológicos que, apesar de apresentarem certa eficiência na remediação de efluentes, possuem várias limitações. Os processos físicos promovem somente uma transferência de fase do contaminante, não sendo, portanto, um método sustentável a médio/longo prazo. Já os processos biológicos possuem uma estreita faixa de condições ótimas ( $\mathrm{pH}$, temperatura, concentração de nutrientes, tempo de residência, etc) nas quais os microorganismos são capazes de utilizarem os poluentes como fonte de matéria-orgâni$\mathrm{ca}^{3}$. Dentre várias outras restrições, destaca-se a inabilidade dos processos biológicos para metabolizarem compostos recalcitrantes, muitos dos quais desenvolvidos para controle de microorganismos (fungicidas, bactericidas, etc.) ou altamente tóxicos para uma ampla gama de organismos. Nestes casos, os processos químicos apresentam-se como a alternativa mais promissora para a degradação das espécies químicas poluentes. A variedade de tratamentos químicos e suas particularidades já foram temas de alguns trabalhos de revisão recentes $^{5-10}$. Deste modo, não serão abordados no presente trabalho; nele será dada atenção especial ao processo químico de ozonização, mais especificamente as novas abordagens que visam aumentar a eficiência deste método na degradação e mineralização de compostos orgânicos poluentes. 


\section{OZÔNIO}

O ozônio vem sendo utilizado no tratamento e desinfecção de águas desde o início do século $\mathrm{XX}^{11}$. Dentre as várias motivações para seu emprego neste tipo de aplicação podem-se destacar duas: é um forte agente oxidante $\left(\mathrm{E}^{0} \cong 2,1 \mathrm{~V}\right)$ e não é uma fonte intrínseca de poluição. A primeira propriedade permite que o ozônio possa oxidar uma série de compostos inorgânicos e orgânicos. Dentre as substâncias químicas ordinárias, somente o flúor possui um potencial de redução maior que o ozônio $\left(\mathrm{E}^{0} \cong 3,0 \mathrm{~V}\right)^{12}$. Outros oxidantes normalmente empregados, tais como $\mathrm{KMnO}_{4}\left(\mathrm{E}^{0} \cong 1,7 \mathrm{~V}\right)$ e $\mathrm{Cl}_{2}$ $\left(\mathrm{E}^{0} \cong 1,4 \mathrm{~V}\right)^{12}$, costumam levar à formação de sub-produtos (íons de metais pesados e compostos organoclorados, respectivamente) que podem ser inclusive mais tóxicos que os compostos poluentes originais. Aqui se evidencia a segunda propriedade vantajosa do ozônio, pois seu produto preferencial de degradação é o oxigênio, um produto não poluente e indispensável para as atividades biológicas aeróbias dos ecossistemas aquáticos ${ }^{13}$.

A molécula de ozônio possui uma geometria triangular, onde o átomo de oxigênio central utiliza orbitais $\mathrm{sp}^{2}$ para formar ligações $\sigma$ com os demais oxigênios. Os orbitais $p_{z}$ dos três oxigênios são utilizados para formar uma ligação $\pi$ deslocalizada, sendo que as duas ligações desta molécula são equivalentes, com comprimentos iguais e ordem de ligação igual a $1,5^{14}$. Devido a este arranjo, o ozônio é dipolar e pode reagir como um agente eletrofílico ou nucleofílico. De modo geral, nas reações de degradação de compostos orgânicos poluentes o ozônio tende a reagir preferencialmente com compostos insaturados (alquenos, alquinos, anéis aromáticos, etc). O ozônio é o reagente clássico usado em reações orgânicas para quebrar ligações duplas carbono-carbono via mecanismo de Criegee (ou simplesmente ozonólise) ${ }^{11,15}$, conforme apresentado na Figura 1. Assim, a oxidação direta de compostos orgânicos por ozônio é uma reação seletiva e que muitas vezes apresenta constantes cinéticas relativamente lentas, com valores típicos entre $10^{-1}$ e $10^{3} \mathrm{~L} \mathrm{~mol}^{-1} \mathrm{~s}^{-1}$, dependendo das espécies envolvidas ${ }^{11,16-}$ 18. Compostos aromáticos com grupos substituintes desativantes, como cloro, sofrem ozonólise mais lentamente que compostos aromáticos com grupos substituintes ativantes, como o grupo hidroxila. Em geral, as formas ionizadas ou dissociadas dos compostos orgânicos reagem muito mais rapidamente com o ozônio que as formas neutras (não dissociadas) ${ }^{15}$. Além disso, as reações de ozonólise direta não costumam promover a oxidação completa dos compostos orgânicos até $\mathrm{CO}_{2}$ e $\mathrm{H}_{2} \mathrm{O}$, sendo aldeídos, cetonas, álcoois e ácidos carboxílicos os principais produtos deste tipo de reação ${ }^{11}$.

(a)

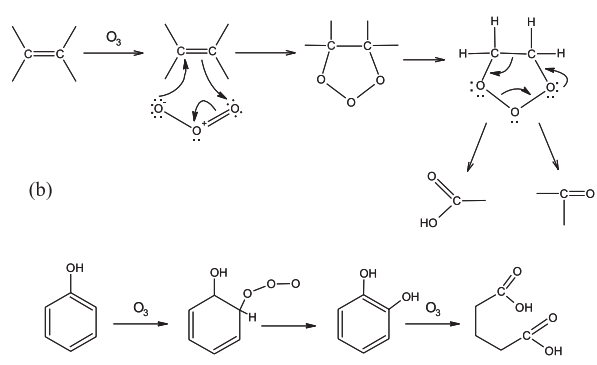

Figura 1. Reação direta do ozônio com a matéria orgânica: mecanismo de Criegee (a). Exemplo de um ataque eletrofílico do ozônio a um composto aromático $(b)$

A limitação cinética, alta seletividade na degradação e baixa eficiência na mineralização de compostos poluentes podem ser contornadas usando-se a alta reatividade e as reações indiretas do ozônio em meio aquoso. $\mathrm{O}_{3}$ é termodinamicamente instável, sendo sua decomposição catalisada por vários materiais ${ }^{19-22}$. Em meio aquoso, o principal desencadeador da decomposição do ozônio é o ânion hidroxila $\left(\mathrm{OH}^{-}\right)$, sendo que a reação entre $\mathrm{O}_{3}$ e $\mathrm{OH}^{-}$desencadeia uma série de reações radicalares que levam à formação de radicais hidroxila. Tal rota de reação é bastante complexa e pode ser influenciada por uma série de fatores experimentais e pela natureza/concentração de espécies químicas presentes. De maneira simplificada, o mecanismo pode ser dividido em três partes, conforme descrito abaixo ${ }^{11,23,24}$ e mostrado na Figura 2:

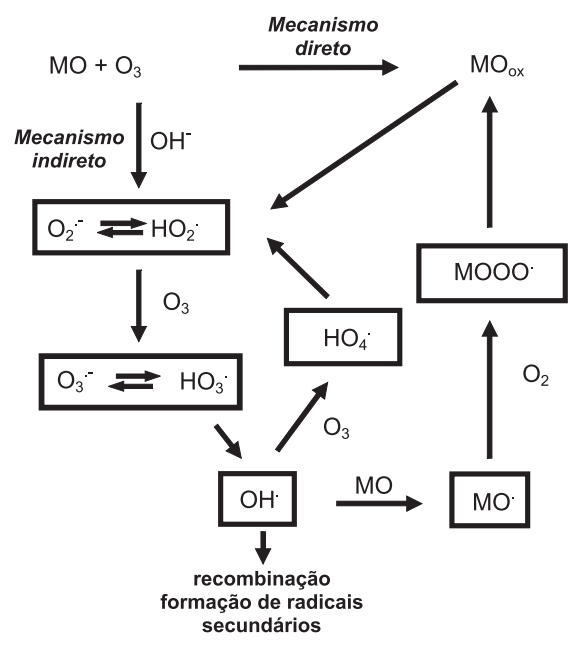

Figura 2. Mecanismos de decomposição direta e indireta do ozônio em meio aquoso $\left(M O=\right.$ matéria orgânica $; \mathrm{O}_{\text {ox }}=$ matéria orgânica oxidada $)$

\section{Iniciação}

A reação entre o íon hidroxila e o ozônio leva a formação do ânion radical superóxido $\mathrm{O}_{2}^{-}$e do radical hidroperoxila $\mathrm{HO}_{2}$ :

$\mathrm{O}_{3}+\mathrm{OH}^{-} \rightarrow \mathrm{O}_{2}^{-}+\mathrm{HO}_{2}$

O radical hidroxila apresenta um equilíbrio ácido-base:

$\mathrm{HO}_{2} \rightleftarrows \mathrm{O}_{2}^{-}+\mathrm{H}^{+}$

\section{Propagação}

O anion radical ozonóide $\left(\mathrm{O}_{3}{ }^{-}\right)$formado da reação entre o ozônio e o ânion radical superóxido $\left(\mathrm{O}_{2}^{-}\right)$decompõe-se, muito rapidamente, para formar os radicais hidroxila.

$\mathrm{O}_{3}+\mathrm{O}_{2}^{\cdot-} \rightarrow \mathrm{O}_{3}^{\cdot-}+\mathrm{O}_{2}$

$\mathrm{HO}_{3} \stackrel{2}{\rightleftarrows} \mathrm{O}_{3}^{-\cdot}+\mathrm{H}^{+}$

$\mathrm{HO}_{3} \cdot \mathrm{OH}+\mathrm{O}_{2}$

$\mathrm{O} \mathrm{OH}$ pode reagir com o ozônio da seguinte maneira:

$\mathrm{OH}^{\cdot}+\mathrm{O}_{3} \rightarrow \mathrm{HO}_{4}^{\cdot}$

$\mathrm{HO}_{4}^{\cdot} \rightarrow \mathrm{O}_{2}+\mathrm{HO}_{2}^{\cdot}$

Com o decaimento de $\mathrm{HO}_{4} \cdot$ para $\mathrm{O}_{2}$ e $\mathrm{HO}_{2} \cdot$ a reação em cadeia pode começar de novo. Substâncias que convertem $\mathrm{OH}^{*}$ para radicais superóxidos $\mathrm{O}_{2}^{-}$e/ou $\mathrm{HO}_{2}{ }^{-}$promovem a reação em cadeia e, devido a isto, são chamadas de promotoras.

Moléculas orgânicas, R, também podem agir como promotoras. 
$\mathrm{H}_{2} \mathrm{R}+\mathrm{OH}^{\cdot} \rightarrow \mathrm{HR}^{\cdot}+\mathrm{H}_{2} \mathrm{O}$

Se oxigênio está presente, radicais orgânicos peroxi ROO podem ser formados. E estes podem reagir em seguida, eliminando $\mathrm{O}_{2}{ }^{-} / \mathrm{HO}_{2}^{*}$ e entrando na reação em cadeia.

$\mathrm{HR}^{\cdot}+\mathrm{O}_{2} \rightarrow \mathrm{HRO}_{2}^{\cdot}$

$\mathrm{HRO}_{2} \rightarrow \mathrm{R}+\mathrm{HO}_{2} \cdot$

$\mathrm{HRO}_{2} \cdot \rightarrow \mathrm{RO}+\mathrm{OH}^{\cdot}$

\section{Terminação}

Algumas substâncias orgânicas e inorgânicas reagem com o radical hidroxila e formam radicais secundários que não produzem $\mathrm{O}_{2}{ }^{*} / \mathrm{HO}_{2}^{*}$, atuando como inibidores das reações em cadeia.

$\mathrm{OH}^{\cdot}+\mathrm{CO}_{3}^{2-} \rightarrow \mathrm{OH}^{-}+\mathrm{CO}_{3} \cdot$

$\mathrm{OH}^{-}+\mathrm{HCO}_{3}^{-} \rightarrow \mathrm{OH}^{-}+\mathrm{HCO}_{3} \cdot$

Outra possibilidade para reação de terminação é a reação entre dois radicais:

$\mathrm{OH}^{\cdot}+\mathrm{HO}_{2}^{\cdot} \rightarrow \mathrm{O}_{2}+\mathrm{H}_{2} \mathrm{O}$

A combinação destas reações mostra que três moléculas de ozônio produzem dois radicais hidroxilas:

$3 \mathrm{O}_{3}+\mathrm{OH}^{-}+\mathrm{H}^{+} \rightarrow 2 \mathrm{OH}+4 \mathrm{O}_{2}$

O radical hidroxila é um dos radicais livres mais reativos e um dos agentes oxidantes mais fortes que se tem notícia $\left(\mathrm{E}^{0} \cong 2,7 \mathrm{~V}\right)$. Outra característica dos radicais hidroxila, que os torna muito eficientes para degradar compostos poluentes, é sua rápida cinética de reação; para compostos orgânicos observam-se constantes entre $10^{6}$ e $10^{10} \mathrm{~L} \mathrm{~mol}^{-1} \mathrm{~s}^{-1}$ (ou seja, atingem valores da mesma ordem de grandeza da constante de difusão do $\mathrm{OH}$ em meio aquoso, $\mathrm{k}_{\mathrm{dif}}=7$ $\left.\mathrm{x} 10^{9} \mathrm{~L} \mathrm{~mol}^{-1} \mathrm{~s}^{-1}\right)$. Além disso, esta espécie é bem menos seletiva que o ozônio, sendo capaz de oxidar uma ampla gama de compostos $^{3,11}$. Devido a estas vantagens, o emprego do ozônio visando a formação de radicais hidroxila (ou seja, atuando como um processo oxidativo avançado - POA) é muito mais versátil e costuma ser a forma mais empregada, principalmente por ser muito eficiente para promover a completa oxidação (mineralização) dos compostos orgânicos poluentes.

Várias abordagens podem ser utilizadas com este intuito, dentre elas destacam-se o uso combinado do ozônio com $\mathrm{OH}^{-}$, radiação UV, $\mathrm{H}_{2} \mathrm{O}_{2}$, ultra-som, etc. A variação do $\mathrm{pH}$ costuma ser a abordagem mais simples (embora não a mais eficiente) para se obter a geração de radicais hidroxila a partir do ozônio. Geralmente, sob condições ácidas $(\mathrm{pH} \leq 4)$ o mecanismo direto (reação de ozonólise) predomina, acima de $\mathrm{pH} 10$ ele se torna predominantemente indireto (reações radicalares). Para águas naturais (superficiais ou subterrâneas) com $\mathrm{pH}$ ao redor de 7, ambos mecanismos podem estar presentes e outros fatores (como tipo do composto alvo e presença de metais de transição) contribuirão para definir a extensão de cada um deles ${ }^{11}$. A Figura 2 esquematiza as duas vias pelas quais o ozônio pode reagir com compostos orgânicos poluentes.

Vários exemplos mostram que o ozônio, quer reagindo de forma direta ou indireta (como um POA), apresenta bons resultados na desinfecção de águas para consumo humano ${ }^{25}$ e na degradação de uma série de compostos poluentes presentes em águas naturais e/ou efluentes (principalmente os oriundos das indústrias têxteis, farmacêuticas, químicas e de papel e celulose) $)^{3,4,26-28}$. Além da es- terilização de uma série de organismos patogênicos, os efeitos depuradores do ozônio são mais pronunciados na remoção de cor (devido à degradação/oxidação de grupos cromóforos) e formação de moléculas menores, com maior hidrofilicidade e menor toxicidade, pois as etapas oxidativas tendem a fragmentar macromoléculas poluentes ${ }^{29-31}$. Geralmente tais transformações contribuem para aumentar a (bio)degradabilidade dos compostos recalcitrantes aos tratamentos biológicos (transformação/oxidação dos poluentes a produtos mais facilmente metabolisados pelos microorganismos). Embora alguns estudos mostrem que os processos de ozonização também podem promover certa redução na demanda química de oxigênio (DQO) e no teor de carbono orgânico total (COT), geralmente os níveis de redução de matéria orgânica são menores que os obtidos com outros POAs ou necessitam de um dispêndio maior de reagentes e/ou energia ${ }^{3,4}$, tornando-os desfavoráveis do ponto de vista econômico.

Devido a estas limitações, vários estudos estão sendo realizados buscando-se aumentar a eficiência dos processos de ozonização, principalmente com relação às taxas de mineralização dos compostos orgânicos poluentes. Neste sentido, o uso do ozônio combinado com metais de transição em solução ou na forma sólida (suportes/sítios ativos heterogêneos) está sendo avaliado por diferentes grupos de pesquisa ${ }^{22,32-35}$. Estas técnicas e suas aplicações serão abordadas e discutidas nas próximas seções que, para efeitos didáticos, foram divididas em função da presença ou não de fases distintas no sistema de degradação.

\section{OZÔNIO CATALÍTICO HOMOGÊNEO}

Pesquisas recentes têm mostrado que a presença de metais de transição pode aumentar a eficiência da oxidação de uma série de espécies poluentes orgânicas por ozônio em meio aquoso $22,32,33,36$. Vários metais de transição podem ser empregados para este fim, dentre eles destacam-se Fe, Mn, Ni, Co, Cd, Cu, Ag, Cr e Zn. O tipo de metal de transição usado no processo de ozonização assistida e a natureza da matriz a ser remediada influem na velocidade da reação, na seletividade, no consumo de ozônio, na taxa de degradação/mineralização e no mecanismo de reação ${ }^{22}$.

Geralmente, dois processos principais são considerados como hipóteses para o mecanismo da ozonização catalítica homogênea: decomposição do ozônio pelo metal, seguida pela geração de radicais e, a formação de complexos entre o catalisador e o composto orgânico, seguido por uma reação final de oxidação.

O processo de decomposição de ozônio por íons metálicos pode seguir diferentes mecanismos que, de modo geral, levam à formação de radicais hidroxila. Hill ${ }^{37,38}$ encontrou evidências experimentais que mostram a geração de radicais hidroxila pela interação direta do ozônio com íons metálicos em meio aquoso:

$\mathrm{M}^{\mathrm{n}+}+\mathrm{O}_{3}+\mathrm{H}_{2} \mathrm{O} \rightarrow \mathrm{MOH}^{\mathrm{n}+}+\mathrm{O}_{2}+\mathrm{OH}$

O autor afirma ainda que o estado de oxidação original do metal pode ser restabelecido, devido a reações paralelas com espécies radicalares, por ex., o radical hidroperoxila.

$\mathrm{HO}_{2}+\mathrm{MOH}^{\mathrm{n}+} \rightarrow \mathrm{M}^{\mathrm{n}+}+\mathrm{O}_{2}+\mathrm{H}_{2} \mathrm{O}$

Também há evidências que o íon metálico presente em solução aquosa pode iniciar a reação de decomposição do ozônio via geração do íon radical $\mathrm{O}_{2}^{-}$. A transferência de elétrons de $\mathrm{O}_{2}^{-}$para a molécula de $\mathrm{O}_{3}$ conduz a formação de $\mathrm{O}_{3}^{-}$(Equação 3) e este, por sua vez, conforme apresentado nas Equações 4 e 5 leva a produção de radicais $\mathrm{OH}^{11}$. 
Vários trabalhos ${ }^{39-41}$ mostram, por ex., que $\mathrm{Fe}^{2+}$ catalisa a decomposição de $\mathrm{O}_{3}$ para gerar radicais hidroxila seguindo um mecanismo distinto. Neste caso, o sistema catalítico $\mathrm{O}_{3} / \mathrm{Fe}^{2+}$ envolve a reação direta de $\mathrm{Fe}^{2+}$ com ozônio, levando à formação do intermediário $\mathrm{FeO}^{2+}$, espécie que promove a formação de $\mathrm{OH}$ :

$\mathrm{Fe}^{2+}+\mathrm{O}_{3} \rightarrow \mathrm{FeO}^{2+}+\mathrm{O}_{2}$

$\mathrm{FeO}^{2+}+\mathrm{H}_{2} \mathrm{O} \rightarrow \mathrm{Fe}^{3+}+\mathrm{OH}+\mathrm{OH}^{-}$

$\mathrm{O}$ intermediário $\mathrm{FeO}^{2+}$ é também capaz de oxidar $\mathrm{Fe}^{2+}$ a $\mathrm{Fe}^{3+}$, mas com uma velocidade menor e esta reação pode limitar a geração de radicais hidroxila, principalmente na presença de altas concentrações de $\mathrm{Fe}^{2+}$ :

$\mathrm{FeO}^{2+}+\mathrm{Fe}^{2+}+2 \mathrm{H}^{+} \rightarrow 2 \mathrm{Fe}^{3+}+\mathrm{H}_{2} \mathrm{O}$

A segunda maneira pela qual o ozônio pode interagir com os metais de transição (mecanismo de complexação) foi proposta por Pines e Reckhow ${ }^{33}$, baseada na ozonização de ácido oxálico na presença de $\mathrm{Co}$ (II) em pH 6. Em uma primeira etapa, um complexo de Co(II)-oxalato é formado, sendo este posteriormente oxidado pelo ozônio, formando o complexo Co(III)-oxalato. Estes autores mostraram que o ataque do ozônio é preferencialmente sobre o centro metálico e a doação parcial de densidade eletrônica do oxalato para o cobalto (II) contribui para aumentar a reatividade do sistema $\mathrm{Co}$ (II)-oxalato, quando comparado com o cobalto livre. O ciclo catalítico é finalizado com a decomposição do complexo de Co(III) e a formação de $\mathrm{Co}(\mathrm{II})$ e o radical oxalato.

$\mathrm{Co}^{2+}+\mathrm{C}_{2} \mathrm{O}_{4}^{2-} \rightleftarrows \mathrm{CoC}_{2} \mathrm{O}_{4}$

$\mathrm{CoC}_{2} \mathrm{O}_{4}+\mathrm{O}_{3} \rightarrow \mathrm{CoC}_{2} \mathrm{O}_{4}^{+}+\mathrm{O}_{3}$

$\mathrm{CoC}_{2} \mathrm{O}_{4}^{+} \rightarrow \mathrm{Co}^{2+}+\mathrm{C}_{2} \mathrm{O}_{4}^{-}$

$\mathrm{C}_{2} \mathrm{O}_{4}^{-}+\mathrm{O}_{2}+\mathrm{O}_{3}+\mathrm{OH}^{-} \rightarrow \mathrm{CO}_{2}+\mathrm{O}_{2}^{-}+\mathrm{O}_{3}^{-}+\mathrm{OH}^{-}$

Observou-se que a remoção de oxalato aumentou com o decréscimo do $\mathrm{pH}$ de 6,7 para 5,3. Este resultado foi muito importante para a elucidação do mecanismo, pois evidencia uma rota distinta das observadas normalmente nos processos de ozonização, onde com a diminuição do valor de $\mathrm{pH}$ (e, conseqüentemente, diminuição da concentração de íons hidroxila que iniciam o processo de decomposição do ozônio e levam à formação de radicais hidroxila) observa-se menor taxa de remoção da matéria orgânica. Além disso, os autores utilizaram uma espécie seqüestradora de radicais hidroxila e não observaram nenhuma mudança na taxa de degradação do ácido oxálico. Tais indícios mostram que a reação direta do ozônio com o complexo Co(II)-oxalato é a responsável pela degradação do ácido oxálico ${ }^{33,42}$.

O mecanismo do processo de ozonização catalítica ainda não está completamente estabelecido e pode variar em função do tipo de espécie metálica empregada, $\mathrm{pH}$, composto-alvo, matriz, etc. Dentre estas variáveis, o estudo de diferentes metais de transição tem recebido grande destaque $22,33,36,39$. Vários metais foram estudados por diferentes grupos de pesquisa, sendo que, mais uma vez, a eficiência destas espécies depende de vários fatores experimentais $^{36,39}$. Entretanto, o consumo de ozônio, a toxicidade do metal, possibilidade de reaproveitamento e o custo também devem ser considerados na avaliação do processo. Ni e colaboradores ${ }^{36}$ exploraram o melhoramento funcional da degradação de uma solução de 2-clorofenol pela adição de vários tipos de íons metálicos durante a ozonização deste composto. $\mathrm{Pb}^{2+}, \mathrm{Cu}^{2+}, \mathrm{Zn}^{2+}, \mathrm{Fe}^{2+}, \mathrm{Ti}^{2+}$ e $\mathrm{Mn}^{2+}$ foram estudados, sendo encontrado que a velocidade da reação de oxidação do composto organoclorado aumentou em todos os casos. Entretanto, o melhor resultado, levando-se em consideração a taxa de mineralização, foi obtido empregando-se manganês, seguido por ferro e titânio. Em pH 3 e com $1 \mathrm{mg} \mathrm{L}^{-1}$ de $\mathrm{Mn}^{2+}$, a velocidade da reação de oxidação do 2-clorofenol aumentou três vezes e houve um aumento de 12,6 para 98\% (em apenas 60 min de tratamento) na remoção de carbono orgânico total. Comparando-se os resultados dos testes com diferentes íons metálicos, encontrou-se que o efeito catalítico em sistemas contendo íons de $\mathrm{Pb}^{2+}, \mathrm{Cu}^{2+} \mathrm{e}$ $\mathrm{Zn}^{2+}$ não era tão evidente. A avaliação da capacidade catalítica (aumento da eficiência de degradação do 2-clorofenol) dos 6 íons metálicos apresentou a seguinte ordem: $\mathrm{O}_{3}$ sozinho $<\mathrm{Pb}^{2+} \approx \mathrm{Cu}^{2+} \approx$ $\mathrm{Zn}^{2+}<\mathrm{Fe}^{2+} \approx \mathrm{Ti}^{2+}<\mathrm{Mn}^{2+}$.

De modo geral, vários trabalhos têm apresentado o manganês como uma das espécies mais promissoras para o processo de ozonização catalítica ${ }^{43-46}$. Ma e Graham $^{43}$ mostraram que uma pequena quantidade de manganês melhora a degradação de pesticidas via reação com ozônio. Neste trabalho, os autores observaram que a redução da concentração de atrazina obtida com o processo de ozonização catalítica (na presença de $0,5 \mathrm{mg} \mathrm{L}^{-1} \mathrm{de} \mathrm{Mn}^{2+}$ ) em apenas 0,5 min é maior que a alcançada com o ozônio sozinho em 2 min. A eficiência de transferência de ozônio para a água também foi maior com o aumento das doses de manganês (II), observandose uma relação aproximadamente linear. Os autores também relatam que o dióxido de manganês formado in situ da reação entre ozônio e Mn(II) pode ter um papel importante na decomposição de ozônio e da destruição catalítica da atrazina.

Foi observado, também, que a presença de substâncias húmicas (consumidoras de radicais) possui uma influência na ozonização da atrazina em presença de manganês. Pequenas quantidades de substâncias húmicas levaram a um melhoramento na oxidação do pesticida, contudo, um aumento na concentração das substâncias húmicas mostrou um efeito negativo sobre a concentração de $\mathrm{Mn}$ (II) e Mn(IV). Em baixas concentrações de substâncias húmicas, ambas as espécies iniciam e promovem a formação do radical hidroxila durante a ozonização, com o melhoramento da destruição da atrazina. Entretanto, em altas concentrações as substâncias húmicas consomem os radicais hidroxila, diminuindo a eficiência de oxidação ${ }^{46}$.

Mesmo apresentando resultados promissores na mineralização de matéria orgânica, o uso de metais pesados no tratamento de água pode não ser recomendável devido à natureza tóxica que estes metais apresentam e, além disso, também deve-se levar em consideração o fator econômico, pois estes metais são relativamente caros e podem ser perdidos durantes as etapas de reação ou exigir etapas laboriosas para sua remoção. Devido a estes fatores, vários estudos estão sendo realizados buscando-se usar metais suportados em, por ex., alumina e sílica ${ }^{47,48}$.

Beltrán e colaboradores ${ }^{49}$ fizeram um estudo mostrando a eficiência do cobalto em solução, imobilizado sobre $\mathrm{Al}_{2} \mathrm{O}_{3}$. Os resultados apresentados para o metal suportado foram bastante promissores e observou-se uma total mineralização do ácido oxálico. $\mathrm{O}$ estudo de metais de transição na forma heterogênea (suportes/sítios ativos heterogêneos) está sendo conduzido por diferentes grupos de pesquisa ${ }^{22,34,35}$ e será foco da próxima seção.

\section{OZÔNIO CATALÍTICO HETEROGÊNEO}

Na ozonização catalítica heterogênea, os principais catalisadores propostos são óxidos de metais $\left(\mathrm{MnO}_{2}, \mathrm{TiO}_{2}, \mathrm{Al}_{2} \mathrm{O}_{3}\right)$ ou também metais ou óxidos de metais em suportes de óxidos de metais (por ex., $\mathrm{Cu}-\mathrm{Al}_{2} \mathrm{O}_{3}, \mathrm{Cu}-\mathrm{TiO}_{2}, \mathrm{Ru}-\mathrm{CeO}_{2}, \mathrm{~V}-\mathrm{O} / \mathrm{TiO}_{2}, \mathrm{~V}-\mathrm{O} /$ sílica gel e $\mathrm{TiO}_{2} /$ $\mathrm{Al}_{2} \mathrm{O}_{3}, \mathrm{Fe}_{2} \mathrm{O}_{3} / \mathrm{Al}_{2} \mathrm{O}_{3}$ ). A atividade depurativa é baseada na decomposição catalítica do ozônio, visando aumentar a geração de radicais hidroxilas. A eficiência da ozonização catalítica depende da 
quantidade do catalisador, das propriedades da superfície e, também, do pH da solução. Neste tipo de oxidação, o catalisador parece ter duas funções: a presença da superfície heterogênea aumenta a dissolução do ozônio e o catalisador também age como iniciador para a reação de decomposição do ozônio ${ }^{22}$.

Vale ressaltar que as reações acontecem tanto na solução como na superfície do catalisador. As duas principais fases da reação em fase aquosa são a decomposição do ozônio que depende do pH e a oxidação da matéria orgânica pelos radicais hidroxila. As reações na superfície devem envolver várias etapas, como adsorção, reação de decomposição do ozônio, reações superficiais de oxidação e processos de dessorção.

Existem basicamente três mecanismos possíveis para a ozonização catalítica em sistemas heterogêneos: quimioadsorção do ozônio na superfície do catalisador, levando à formação de espécies ativas que reagem com moléculas orgânicas não adsorvidas; quimioadsorção da matéria orgânica na superfície do catalisador e sua posterior reação com o ozônio aquoso ou gasoso e, quimioadsorção de ambos, ozônio e molécula orgânica, e sua posterior interação (Figura 3).

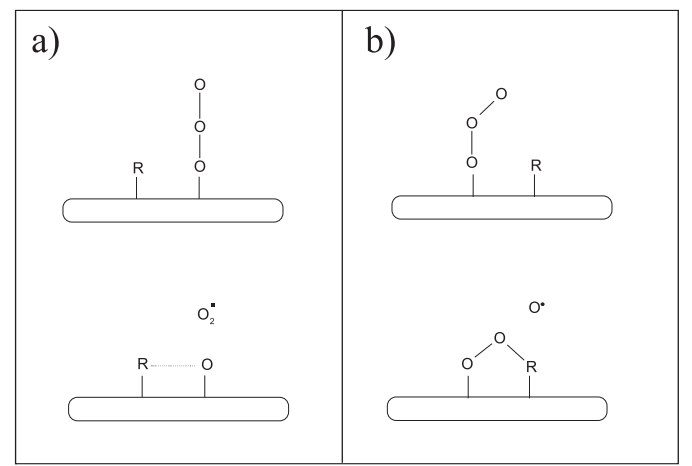

Figura 3. Diferentes formas de interação do ozônio com a matéria orgânica adsorvida na superfície do metal, formação de $\mathrm{O}_{2}$ (a) e formação de $\mathrm{O}(\mathrm{b})$

Vários óxidos metálicos (especialmente alumina, titânio e sílica) são utilizados como superfície ativa para o processo de ozonização catalítica. Estes óxidos são os mais empregados, principalmente devido as suas características físicas (área superficial; densidade; volume, quantidade e tamanho de poro; resistência mecânica, etc.) e químicas (estabilidade química e presença de sítios ativos na superfície, principalmente sítios ácidos de Lewis).

Um dos principais parâmetros que determinam a propriedade catalítica do óxido utilizado é a acidez ou basicidade de sua superfície. Grupos hidroxila estão presentes em todas as superfícies de óxidos metálicos, entretanto, a quantidade e propriedade destes grupos dependem da natureza do óxido ${ }^{50}$. Bulanin e colaboradore ${ }^{51}$ concluíram que a adsorção de ozônio sobre a superfície de óxidos do tipo $n$ resulta na produção de oxigênio e/ou oxidação da superfície. Já a interação do ozônio com óxidos do tipo $p$ leva à decomposição do ozônio via formação de espécies radicalares (principalmente o ânion radical superóxido). Comportamento semelhante foi observado variando-se o $\mathrm{pH}$ do meio reacional, conforme mostram as Equações 25 a 31 ( $\mathrm{S}=$ sítio ativo da superfície do óxido metálico ${ }^{22}$.

Reações na superfície em meio ácido

$\mathrm{O}_{3}+\mathrm{S} \rightleftarrows \mathrm{O}_{3}-\mathrm{S}$

$\mathrm{O}_{3}-\mathrm{S} \rightleftarrows \mathrm{O}-\mathrm{S}+\mathrm{O}_{2}$

$\mathrm{O}_{3}+\mathrm{O}-\mathrm{S} \rightleftarrows 2 \mathrm{O}_{2}+\mathrm{S}$
Reações na superfície em meio básico

$\mathrm{OH}^{-}+\mathrm{S} \rightleftarrows \mathrm{OH}-\mathrm{S}$

$\mathrm{O}_{3}+\mathrm{OH}-\mathrm{S} \rightleftarrows \mathrm{O}_{3}-\mathrm{S}+\mathrm{HO}$

$\mathrm{O}_{3}-\mathrm{S} \rightleftarrows \mathrm{O}-\mathrm{S}+\mathrm{O}_{2}$

$\mathrm{O}_{3}+\mathrm{O}-\mathrm{S} \rightleftarrows \mathrm{O}_{2} \cdot+\mathrm{S}+\mathrm{O}_{2}$

A seguir serão apresentados e discutidos alguns exemplos de aplicação dos principais catalisadores usados na ozonização catalítica heterogênea.

O dióxido de titânio é bastante usado nos processos de tratamento de água, devido a muitas características, entre elas alta atividade fotocatalítica, baixa toxicidade, insolubilidade na água e baixo custo ${ }^{52}$. Diferentes experimentos usando ozônio, $\mathrm{TiO}_{2}$ e a combinação destes foram feitos para analisar a degradação de uma série de compostos poluentes, tais como organoclorados, pesticidas, fenóis, vários compostos orgânicos nitrogenados, etc ${ }^{53-58}$. De modo geral, todos estes trabalhos mostraram uma taxa de degradação dos poluentes maior pelo emprego do processo fotocatalítico combinado com ozônio que para os processos isolados.

Um exemplo do efeito sinérgico entre $\mathrm{TiO}_{2}$ e $\mathrm{O}_{3}$ foi observado por Sanchez e colaboradores ${ }^{53}$ na degradação de anilina. Avaliando a degradação de uma solução $1300 \mathrm{mg} \mathrm{L}^{-1}$ de anilina, observaram uma redução de COT de $97 \%$ com o sistema combinado fotocatálise/ ozônio, após $7 \mathrm{~h}$ de tratamento. Os processos isolados de fotocatálise e ozonização permitiram, para o mesmo período de tratamento, uma redução de COT de somente 44 e $9 \%$, respectivamente. Este comportamento pode ser compreendido considerando-se que o ozônio é um agente efetivo para degradação de anilina e compostos aromáticos intermediários, que costumam ser degradados lentamente pelo processo de fotocatálise heterogênea. Deste modo, depois da ozonização, o processo fotocatalítico pode atuar sobre produtos mais facilmente oxidáveis, aumentando as taxas de degradação do processo global. Um outro mecanismo que pode explicar o aumento na eficiência do processo combinado é a atuação do ozônio como aceptor de elétrons fotogerados na superfície do $\mathrm{TiO}_{2}$ durante o processo fotoquímico. Esta interação leva à produção do ânion radical ozonóide, que é um intermediário para a formação do radical hidroxila (Figura 4). No processo de fotocatálise/TiO/ ozônio tem-se, dentre outras, as seguintes reações envolvidas:

$\mathrm{TiO}_{2}+\mathrm{hv} \rightarrow \mathrm{e}_{\mathrm{BC}}{ }^{-}+\mathrm{h}_{\mathrm{BV}}{ }^{+}$

$\mathrm{H}_{2} \mathrm{O}+\mathrm{h}_{\mathrm{BV}}{ }^{+} \rightarrow \mathrm{OH}+\mathrm{h}_{\mathrm{BV}}{ }^{+}$

$\mathrm{O}_{3}+\mathrm{e}_{\mathrm{BC}} \rightarrow \mathrm{O}_{3}$

$\mathrm{O}_{3} \cdot{ }^{-\cdot}+\mathrm{H}^{+} \rightarrow \mathrm{OH}+\mathrm{O}_{2}$

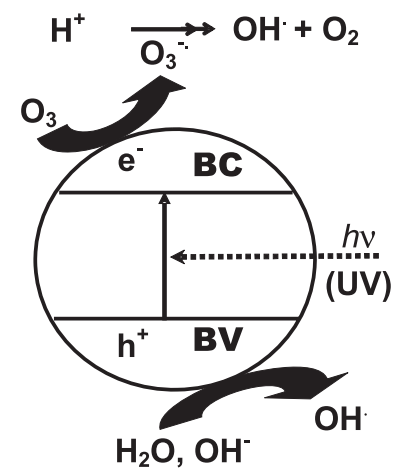

Figura 4. Mecanismo de interação do ozônio com a superfície do dióxido de titânio levando a produção do ânion radical ozonóide $(B C=$ Banda de condução; $B V=$ banda de valência $; e^{-}=$elétron $; h^{+}=$lacuna) 
A presença de ozônio pode diminuir a recombinação dos elétrons com as lacunas, levando à maior geração de radicais hidroxilas e, conseqüentemente, à melhor eficiência do processo fotocatalítico. $\mathrm{O} \mathrm{O}_{3}$ é melhor aceptor de elétrons que o $\mathrm{O}_{2}$ (que é a substância mais utilizada para esta função) e, devido a isto, há melhoras na eficiência e cinética do processo ${ }^{39,40}$.

A alumina também tem se mostrado bastante efetiva para catalisar a oxidação de compostos orgânicos poluentes pelo ozônio. Ni e Chen ${ }^{59}$, estudando a degradação de 2-clorofenol por $\mathrm{O}_{3}$ e $\mathrm{O}_{3} / \mathrm{Al}_{2} \mathrm{O}_{3}$, observaram um aumento na redução do teor COT de aproximadamente $84 \%$ quando empregaram a alumina. $\mathrm{O}$ mecanismo proposto neste caso também consiste na adsorção simultânea do ozônio e da molécula orgânica na superfície do catalisador. A decomposição do ozônio ocorre nos sítios metálicos, produzindo radicais $\mathrm{O}^{-}$ligados, que são mais reativos que o ozônio e este, por consequiência, oxida moléculas orgânicas adjacentes. $\mathrm{O}$ radical anion $\mathrm{O}^{-}$é continuamente gerado pelo ozônio dissolvido e transferido para a superfície do catalisador. A afinidade dos produtos oxidados pelo catalisador decresce e os produtos finais de oxidação dessorvem da superfície do catalisador ${ }^{60}$.

Além da utilização de óxidos de metais de transição em suspensão, há vários estudos relatando o emprego de $\mathrm{TiO}_{2}, \mathrm{MnO}_{2}, \mathrm{Fe}_{2} \mathrm{O}_{3}$ e outros óxidos imobilizados sobre suportes, tais como sílica gel, argila, alumina, etc ${ }^{47,48,52,61-67}$. Além da natureza dos óxidos e de suas características superficiais, as propriedades catalíticas destes sistemas também dependerão fortemente do método de preparação (síntese e tratamentos térmicos e químicos). Gracia e colaboradores ${ }^{52,61,62}$ avaliaram a degradação de ácido húmico por três diferentes sistemas $\mathrm{TiO}_{2} / \mathrm{SiO}_{2} / \mathrm{O}_{3}, \mathrm{TiO}_{2} / \mathrm{Al}_{2} \mathrm{O}_{3} / \mathrm{O}_{3}$ e $\mathrm{TiO} /$ argila/ $\mathrm{O}_{3}$. Além do tipo de suporte, os autores também estudaram o efeito da temperatura de calcinação e a dose ótima de catalisador. Observaram maior taxa de remoção de COT para o processo de ozonização catalítica usando $\mathrm{TiO}_{2} /$ alumina calcinada a $500{ }^{\circ} \mathrm{C}$.

Cooper e Burch ${ }^{63}$ também mostraram uma influência significativa da alumina no aumento da decomposição catalítica do ozônio e da degradação de compostos orgânicos. Estudando os sistemas $\mathrm{TiO}_{2} / \mathrm{Al}_{2} \mathrm{O}_{3}$ e $\mathrm{Fe}_{2} \mathrm{O}_{3} / \mathrm{Al}_{2} \mathrm{O}_{3}$, concluíram que a imobilização sobre alumina permitiu um aumento na remoção de ácido oxálico, cloroetanol e clorofenol de águas contaminadas.

A eficiência catalítica de $\mathrm{Al}_{2} \mathrm{O}_{3}, \mathrm{SiO}_{2}$ e carvão ativo impregnados com Pt, Pd, Ag, Co, Ru, Ir, Rh e Re na ozonização de ácido fórmico foi estudada por Lin e colaboradores ${ }^{67}$. Utilizando somente os suportes sem a presença de metais, observaram que $\mathrm{TiO}_{2}$ e carvão ativo mostraram os melhores resultados, enquanto que $\mathrm{Al}_{2} \mathrm{O}_{3}$ e $\mathrm{SiO}_{2}$ praticamente não apresentaram atividade catalítica. Já para os suportes impregnados com metais, obteve-se melhor eficiência para $\mathrm{Pt} / \mathrm{Al}_{2} \mathrm{O}_{3}$ e $\mathrm{Pd} / \mathrm{Al}_{2} \mathrm{O}_{3}$.

A natureza do composto a ser degradado também é um fator de extrema importância para a eficiência dos processos de ozonização catalítica, principalmente considerando-se o processo de adsorção física como uma das etapas limitantes. Neste sentido, o uso de carvão ativo, que atua como um importante adsorvente, tem sido bastante estudado também para promover aumento na eficiência dos processos de oxidação via ozônio. O carvão ativo é muito usado para tratamento de água, devido a sua propriedade adsorvente, que promove a remoção de micropoluentes hidrofóbicos. Entretanto, este apresenta também propriedades catalíticas, devido a sua grande área superficial e os grupos funcionais que ativam a superfície.

Rivera-Útrilla e colaboradores ${ }^{68}$ observaram que o carvão ativo aumenta a decomposição de ozônio para espécies radicalares altamente oxidantes, aumentando a eficiência do processo. Propuseram que centros metálicos de materiais minerais presentes no carvão ativo, os elétrons dos carbonos no plano basal (elétrons $\pi$ deslocalizados, que podem atuar como centros catalíticos através da redução do ozônio, Equação 36) e as espécies/grupos funcionais oxigenados presentes na superfície do carbono (Equação 37), são os principais responsáveis pela decomposição do ozônio em meio aquoso.

$\mathrm{O}_{3}+\mathrm{H}_{2} \mathrm{O}+2 \mathrm{e}^{-} \rightarrow \mathrm{O}_{2}+2 \mathrm{OH}^{-}$

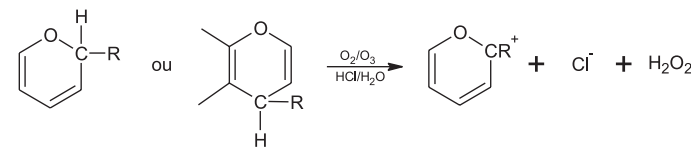

Faria e colaboradores ${ }^{69}$ também estudaram o efeito sinérgico entre carvão ativo e ozônio e mostraram que, inicialmente, o carvão ativo sozinho não foi capaz de remover completamente a cor de soluções de três diferentes corantes em um tempo razoável. Por outro lado, a ozonização sozinha descolore rapidamente a solução, mas não promove boa redução de COT. A combinação de carvão ativo com ozônio melhorou a descoloração das soluções e especialmente a mineralização da matéria orgânica, sendo que o carvão ativo agiu como adsorvente e catalisador da reação. Neste tipo de associação, o ozônio promove a degradação das moléculas de corante, que possuem uma estrutura grande, produzindo moléculas de massa molar menor, devido ao ataque ao grupo cromóforo e rompimento de ligações. Como discutido anteriormente, o ozônio é eficiente para descolorir a solução, mas apresenta baixa taxa de remoção de COT. A adsorção em carvão ativado leva a uma redução de matéria orgânica em solução. O problema é que quando se trata uma água com alto teor de matéria orgânica, o adsorvente é saturado facilmente, exigindo regeneração ou substituição. Além disso, o poluente não é de fato mineralizado mas sim, transferido de fase. A combinação de ozônio e carvão ativo tem se mostrado como uma boa alternativa para tratamento de água contendo corantes ou outros compostos orgânicos. A remoção de COT por ozonização na presença do carvão ativo é maior que a obtida pela soma da oxidação seguida pela adsorção e, assim, tem-se um efeito sinérgico, evidenciando que o carvão não age só como adsorvente, mas como catalisador dos processos de ozonização. A alta capacidade adsortiva do carvão ativo e sua atividade catalítica para decomposição do ozônio tem sido relatada como altamente eficaz para depuração de soluções contaminadas com compostos orgânicos poluentes via processos de ozonização (pois observa-se claramente um aumento significativo na remoção de matéria orgânica) ${ }^{22,68,69}$.

Uma outra vantagem deste método é a possibilidade da regeneração contínua do carvão ativo mediado pelo ozônio. Recentemente foi conduzida uma investigação para regenerar carvão ativo granulado, usando ozônio como agente regenerador. A regeneração depende do mecanismo de adsorção da matéria orgânica e do efeito de interação entre ozônio e carvão ativo, pois as propriedades do carbono, como textura e química da superfície, podem ser modificadas quando expostas ao ozônio. Segundo resultados obtidos, o carvão ativo granulado virgem apresentou área superficial, volume do poro e microporosidade maiores que as observadas com outras amostras de carvão já expostas ao ozônio. Este trabalho mostrou que há perda de somente $10 \%$ da área superficial do carvão tratado, apresentado grande possibilidade de reutilização deste material ${ }^{70}$.

Rivera-Utrilla e colaboradores ${ }^{68}$ escolheram o ácido 1,3,6naftalenotrisulfônico (NTS) como composto modelo para avaliar a ozonização do mesmo na ausência e presença de diferentes carvões ativos. De acordo com estudos anteriores ${ }^{71,72}$, este contaminante é caracterizado por sua baixa reatividade frente ao ozônio e ao carvão ativo, isoladamente. Os autores observaram que a degradação de NTS 
via ozonização foi maior na presença do carvão que na sua ausência. Além disso, a taxa de degradação aumentou em função da diminuição do tamanho de partícula do carvão ativo. Em outro trabalho ${ }^{73}$, estes mesmo autores mostram que a degradação de NTS pode ser melhorada na presença de carvões com alto teor de cinzas e altas concentrações de grupos básicos, pois ambos podem decompor o ozônio em espécies mais reativas. Para quantificar a extensão em que a matéria inorgânica presente no carvão ativo afeta a ozonização, foram realizados experimentos usando carvão desmineralizado. Nestes casos, a taxa de degradação do NTS foi muito reduzida. Os autores concluíram que a atividade catalítica durante a ozonização do composto orgânico era devida aos metais intrinsecamente presentes nos materiais minerais do carvão ativo usado.

Embora ainda não haja muitos exemplos de aplicação destas novas vertentes no tratamento de amostras reais, alguns estudos mostram que os mesmos são bastante promissores. Moraes e colaboradores $^{30}$, por ex., estudaram a degradação de efluentes têxteis empregando $\mathrm{TiO}_{2} / \mathrm{UV} / \mathrm{O}_{3}$. Além de observarem um aumento significativo na descoloração e redução de matéria orgânica, também constataram que o uso de ozônio junto com $\mathrm{TiO}_{2}$ promovia maior redução na toxicidade dos efluentes que qualquer um dos processos isolados.

Como pode-se observar nos trabalhos discutidos anteriormente, além do estudo das reações do ozônio em solução e de sua interação com o metal, há muito para ser estudado, considerandose a química de superfície dos suportes. Neste sentido, todo o avanço que tem sido obtido com o desenvolvimento e estudo de novos materiais pode contribuir para aprimorar o entendimento e a eficiência dos processos de ozonização catalítica heterogênea, principalmente com a utilização de materiais nanoestruturados.

\section{CONSIDERAÇÕES FINAIS}

A Química tem ocupado um lugar de destaque na busca de novos processos produtivos que sejam menos impactantes, no desenvolvimento de materiais ecologicamente compatíveis e no estudo de tratamentos para remediação de recursos/sistemas naturais degradados pela presença de compostos poluentes. Neste sentido, o uso do ozônio como agente de oxidação vem crescendo sistematicamente ao longo das últimas décadas. Vários países já utilizam esta espécie como agente desinfetante durante o tratamento de águas para consumo humano. Apesar de sua grande eficiência na remoção de microorganismos patogênicos e oxidação de compostos orgânicos poluentes, a aplicação em larga escala do ozônio no tratamento de efluentes industriais ainda não é uma realidade. Dentre as principais limitações destaca-se a baixa solubilidade do ozônio, que diminui a transferência de massa da fase gasosa para a líquida, levando a uma baixa razão entre concentração de ozônio/quantidade de matéria degradada. Além disso, a seletividade e o custo de implementação dos sistemas de ozonização também contribuem para restringir a aplicabilidade do ozônio.

Neste trabalho foram apresentadas algumas alternativas que podem minimizar alguns problemas decorrentes do emprego de ozônio no tratamento de compostos poluentes em meio aquoso. De modo geral, o uso de metais de transição aumenta a eficiência deste processo, principalmente por meio da geração de espécies radicalares com características fortemente oxidantes e não seletivas. Os mecanismos discutidos neste trabalho ainda não estão completamente consolidados e estudos mais aprofundados devem ser realizados, visando elucidar melhor as etapas envolvidas neste tipo de tratamento, principalmente com relação às variáveis reacionais e propriedades superficiais. Estes estudos estão inseridos dentro de um amplo campo de pesquisa, que permite aliar conhecimentos fundamentais com resolução de problemas práticos de extrema pertinência.

Neste sentido, a ozonização catalítica tem um grande potencial para ser empregada eficientemente na remediação de matrizes reais e complexas, apresentando-se como uma alternativa promissora para minimizar os efeitos deletérios que várias atividades antropogênicas têm provocado nos ecossistemas aquáticos.

\section{AGRADECIMENTOS}

Ao CNPq, à CAPES e FAPESP pelo apoio financeiro.

\section{REFERÊNCIAS}

1. Rebouças, A.; Braga, B.; Tundisi, J.; Águas Doces no Brasil, $2^{\mathrm{a}}$ ed., Escrituras Ed.: São Paulo, 2002.

2. Branco, S. M.; Água: origem, uso e preservação, Ed. Moderna: São Paulo, 1993.

3. Freire, R. S.; Pelegrini R.; Kubota L. T.; Durán N.; Quim. Nova 2000, 23, 504.

4. Pereira, W. S.; Freire, R. S.; Quim. Nova 2005, 28, 130.

5. Herrmann, J. M.; Catal. Today 1999, 53, 115.

6. Pera-Titus, M.; García-Molina, V.; Baños, M. A.; Jiménez, J.; Esplugas, S.; Appl. Catal., B 2004, 47, 219.

7. Alvares, A. B. C.; Diaper, C.; Parsons, S. A.; Environ. Technol. 2001, 22, 409.

8. Wang, F.; Smith, D. W.; El-Din, M. G.; J. Environ. Eng. Sci. 2003, 2, 413.

9. Gogate, P. R.; Pandit, A. B.; Adv. Environ. Res. 2004, 8, 501.

10. Gogate, P. R.; Pandit, A. B.; Adv. Environ. Res. 2004, 8, 553.

11. Gottschalk, C.; Libra, A. J.; Saupe, A.; Ozonation of water and waste water, WILEY-VCH: Weinheim, 2000.

12. Atkins, P. W.; Physical chemistry, $7^{\text {th }}$ ed., Oxford: New York, 2002.

13. Manahan, S. E.; Enviromental Chemistry, $8^{\text {th }}$ ed., CRC Press: Boca Raton, 2005.

14. Lee, J. D.; Química inorgânica não tão concisa, $2^{\text {a }}$ ed., Ed. Edgard Blücher: São Paulo, 2001.

15. McMurry, J.; Química Orgânica, 6ª ed., Ed. Pioneira Thomson Learning: São Paulo, 2005.

16. Hoigné, J.; Bader, H.; Water Res. 1983, 17, 173.

17. Hoigné, J.; Bader, H.; Water Res. 1983, 17, 185.

18. Hoigné, J.; Bader, H.; Water Res. 1985, 19, 993.

19. Dhandapani, B.; Oyama, S. T.; Appl. Catal., B 1997, 11, 129.

20. Alebic-Juretic, A.; Cvitas, T.; Klasinc, L.; Chemosphere 2000, 41, 667.

21. Lin, J.; Kawai, A.; Nakajima, T; Appl. Catal., B 2002, 39, 157.

22. Kasprzyk-Hordern, B.; Ziólek, M.; Nawrocki, J.; Appl. Catal., B 2003, 46, 639.

23. Mao, H.; Smith, D.; Ozone: Sci. Eng. 1995, 17, 205.

24. Staehelin, J.; Holgné, J.; Environ. Sci. Technol. 1985, 19, 1206.

25. Kool, H. J.; Hrubec, J.; Ozone: Sci. Eng. 1986, 8, 217.

26. Silva, L. M.; Jardim, W. F.; Quim. Nova 2006, 29, 310.

27. Almeida, E.; Assalin, M. R.; Rosa, M. A.; Quim. Nova 2004, 27, 818.

28. Balcioglu, I. A.; Otker, M.; Chemosphere 2003, 50, 85.

29. Freire, R. S.; Kunz, A.; Durán, N.; Environ. Technol. 2000, 21, 717.

30. Moraes, S. G.; Freire, R. S.; Durán, N.; Chemosphere 2000, 40, 369.

31. Freire, R. S.; Kubota, L. T.; Durán, N.; Environ. Technol. 2001, 22, 897.

32. Legube, B., Karpel, V. L. N.; Catal. Today 1999, 53, 61.

33. Pines, D. S.; Reckhow D. A.; Environ. Sci. Technol. 2002, 36, 4046.

34. Farré, M. J.; Franch, M. I.; Malato, S.; Ayllón, J. A.; Peral. J.; Doménech, X.; Chemosphere 2005, 58, 1127.

35. Beltrán, F. J.; Rivas, J., Álvez, P.; Montero-de-Espinosa, R.; Ozone: Sci. Eng. 2002, 24, 227.

36. Ni, C. H.; Chen, J. N.; Yang P. Y.; Water Sci. Technol. 2002, 47, 77.

37. Hill, G.; J. Am. Chem. Soc. 1948, 70, 1306.

38. Hill, G.; J. Am. Chem. Soc. 1949, 71, 2434.

39. Sauleda, R.; Brillas, E.; Appl. Catal., B 2001, 29,135.

40. Piera, E.; Calpe, J. C.; Brillas, E.; Doménech, X.; Peral, J.; Appl. Catal., B 2000, 27, 169.

41. Arslan, I.; Balcioglu, I. A.; Tuhkanen, T.; Water Sci. Technol. 2000, 42, 13.

42. Beltrán, F. J.; Rivas, F. J.; Montero-de-Espinosa, R.; Ind. Eng. Chem. Res. 2003, 42, 3210 .

43. Andreozzi, R.; Caprio, V.; Insola, A.; Marotta, R. T.; Tufano V.; Water Res. 1998, 32, 1492 .

44. Andreozzi, R.; Caprio, V.; Insola, A.; Marotta, R., T.; Tufano V.; Water Res. 2001, 35, 109. 
45. Ma, J.; Graham, J. D.; Ozone: Sci. Eng. 1997, 19, 227.

46. Ma, J.; Graham, J. D.; Water Res. 1999, 33, 785.

47. Rakitskaya, T. L.; Ennan, A. A.; Granatyuk, I. V.; Bandurko, A. Y. Balavoine, G. G. A.; Geletii, V. Y.; Paina, V. Y.; Catal. Today 1999, 53, 715 .

48. Einaga, H.; Harada, M.; Futamura, S.; Chem. Phys. Lett. 2005, 408, 377.

49. Beltrán, F. J.; Rivas, F. J.; Montero-de-Espinosa, R.; Ind. Eng. Chem. Res. 2003, 42, 3218 .

50. Nawrocki, J.; Rigney, M. P.; McCormick, A.; Carr, P.W.; J. Chromatogr., A 1993, 657, 229.

51. Bulanin, K. M.; Lavalley, J. C.; Tsyganenko, A. A.; J. Phys. Chem. 1994, 99, 10294.

52. Gracia, R.; Cortés, S.; Sarasa, J.; Ornad, P.; Ovelleiro, J. L.; Ozone: Sci. Eng. 2000, 22, 461.

53. Sánchez, L.; Peral, J.; Domènech, X.; Appl. Catal., B 1998, 19, 59.

54. Gilbert, E.; Ozone Sci. Eng. 2002, 24, 75.

55. Tanaka, K.; Abe, K.; Hisanaga, T.; J. Photochem. Photobiol., A 1996, 101, 85

56. Klare, M.; Waldner, G.; Bauer, R.; Jacobas, H.; Broekaert, J. A. C.; Chemosphere 1999, 38, 2013

57. Volk, C.; Roche, P.; Joret, J. C.; Paillard, H.; Water Res. 1997, 31, 650.

58. Beltrán. F. J.; Rivas, F. J.; Gimeno, O.; Carbajo, M.; Ind. Eng. Chem. Res. 2005, 44, 3425 .
59. Ni, C. H.; Chen, J. N.; Water Sci. Technol. 2001, 43, 213.

60. Legrini, O.; Oliveros, E.; Braun, A. M.; Chem. Rev. 1993, 93, 671.

61. Gracia, R.; Cortés, S.; Sarasa, J.; Ormad, P.; Ovelleiro, J. L.; Ozone: Sci. Eng. 2000, 22, 185.

62. Gracia, R.; Cortés, S.; Sarasa, J.; Ormad, P.; Ovelleiro, J. L.; Water. Res. 2000, 34, 1525.

63. Cooper, C.; Burch, R.; Water Res. 1999, 33, 3695.

64. Al-Hayek, N.; Legube, B.; Dore, M.; Environ. Technol. Lett. 1989, 10, 415.

65. Ping, T. S.; Hua, L. W.; Qing, Z. J.; Nan, C. C.; Ozone: Sci. Eng. 2002, 24,117

66. Villaseñor, J.; Reyes, P.; Pecchi, G.; Catal. Today 2002, 76, 121.

67. Lin, J.; Nakajima, T.; Jomoto, T.; Hiraiwa, K.; Ozone: Sci. Eng. 2000, 22, 241.

68. Rivera-Útrilla, J.; Sánchez-Polo, M.; Appl. Catal., B 2002, 39, 319

69. Faria, P. C. C.; Orfão, J. M.; Pereira, M. F. R.; Water Res. 2005, 39, 1461.

70. Álvarez, P. M.; Garcia-Araya, J. F.; Beltrán, F. J.; Masa, F. J.; Medina, F.; J. Colloid Interface Sci. 2005, 283, 503.

71. Sánchez-Polo, M.; Rivera-Utrilla, J.; Zaror, C. A.; J. Chem. Technol. Biotechnol. 2002, 77, 148

72. Rivera-Utrilla, J.; Sánches-Polo, M.; Zaror, C. A.; Phys. Chem. Chem. Phys. 2002, 4, 148

73. Sánchez-Polo, M.; Leyva-Ramos, R.; Rivera-Útrilla, J.; Carbono 2005, 43, 962. 